\title{
Zinc Utilization and Associated Factors Among Under-five Children Having Acute Diarrhea in Kebri-dehar Town, Somali Region, Ethiopia-2017
}

\author{
Ebud Ayele ${ }^{1}$, Hagos Tasew ${ }^{2}$, Teklewoini Mariye ${ }^{2}$, Girmay Teklay ${ }^{2}$, Tadesse Alemayhu ${ }^{3}$, \\ Frehiwot Mesfin ${ }^{3}$ \\ ${ }^{1}$ Department of Public Health Nutrition, College of Medicine and Health Sciences, Axum University, Axum, Ethiopia \\ ${ }^{2}$ Department of Nursing, College of Medicine and Health Science, Axum University, Axum, Ethiopia \\ ${ }^{3}$ Department of Public Health, College of Health and Medical Sciences, Haramaya University, Harar, Ethiopia
}

Email address:

addressebudayele@gmail.com (E. Ayele), tasewh2@gmail.com (H. Tasew), teklewoini1@gmail.com (T. Mariye), tadessewon@yahoo.com (T. Alemayhu), firehiwotm@gmail.com (F. Mesfin)

\section{To cite this article:}

Ebud Ayele, Hagos Tasew, Teklewoini Mariye, Girmay Teklay, Tadesse Alemayhu, Frehiwot Mesfin. Zinc Utilization and Associated Factors Among Under-five Children Having Acute Diarrhea in Kebri-dehar Town, Somali Region, Ethiopia-2017. Pathology and Laboratory Medicine. Vol. 4, No. 1, 2020, pp. 15-19. doi: 10.11648/j.plm.20200401.13

Received: September 30, 2019; Accepted: October 14, 2019; Published: April 23, 2020

\begin{abstract}
Introduction: Zinc with Oral Rehydration Solution was recommended for the management of children's with acute diarrhea. Zinc can resist subsequent episodes of diarrhea for up to $2-3$ months and decrease $23 \%$ mortality due to diarrhea. Therefore, zinc is one strategy to decrease child mortality in developing countries like Ethiopia. However, there is limited evidence regarding utilization of zinc and associated factors in the eastern part of Ethiopia, Somali region. Objective: To assess the magnitude of zinc utilization and associated factors in Somali region, eastern Ethiopia. Method: Community based crosssectional study design in 2017 was applied. Simple random sampling was applied. Total sample size of 376 randomly selected under-five children who have been acute diarrheal were selected. Data was collected by face-to-face inter-viewer administered questionnaire by ten data collectors. The collected data was entered into EpiData3.1 and then exported and analysed using SPSS20. Bivariate \& multivariate logistic regression analysis was done to identify factors associated with zinc utilization at confidence level of $95 \%$ and P-value less than $5 \%$ significant. Frequencies, proportion, summary statistics were used for presenting the result of the study. Result: Nearly all $374(99.4 \%)$ mothers with children pairs were participated in the study. The magnitudes of zinc utilization were found to be $29.1 \%$ (95\% CI, $24.49 \%-33.71 \%)$. zinc was less utilized by mothers who were having no formal education [(AOR $=0.181,95 \% \mathrm{CI}$ : $(.056, .591)]$, child age $6-11$ months [(AOR $=0.130,95 \%$ CI: $(.025, .683)]$, Mothers withhold food and fluid during acute diarrhea [(AOR $=.185,95 \%$ : CI: $(.068, .502)]$ and no husband formal education [(AOR $=0.050,95 \%$ CI: $(.020, .128)]$. conclusion: In this study zinc tablet where utilized by the child with diarrhea, that is Less than the magnitude of national utilization. Mothers having no formal education, child age 6-11 months, Mothers withhold food and fluid during acute diarrhea and husband formal education, were significant associated factors.
\end{abstract}

Keywords: Utilization, Zinc, Acute Diarrhea, Kebri-dehar

\section{Introduction}

Globally, an estimated 2.5 billion cases of diarrhea occur among children less than 5 years of age each year, more than half of these cases occur in Africa and South-east Asia [1]. According to United Nations International Children's Emergency Fund (UNICEF), approximately 30,000 children in Ethiopia die each year from a diarrhea disease - something that is easy to treat [2]. World health organization and United Nations Children's Fund recommend 10-14 days of zinc treatment for under-five children with each diarrhea illness that can shortens the diarrhea episode, reduces the risk of the episode being persistent, reduces the risk of future diarrhea and reduces overall mortality [3]. Drivers knowledge Test Ethiopia (DKT/E) and the Micronutrient Initiative (MI), under the leadership of the federal ministry of health, 
maternal and child health directorate and nutrition section, launched a combined ORS and Zinc product treat childhood diarrhea which is, one of the leading cause of illness and child mortality in Ethiopia. This simple and cost-effective helps children resist subsequent episodes of diarrhea for up to 2 - 3 months [4]. Especially Zinc is an effective therapy for diarrhea and will decrease diarrhea morbidity and mortality when introduced and scaled-up in low-income countries, and its supplementation decreased the proportion of diarrheal episodes which lasted beyond 7 days, risk of hospitalization and Zinc for the treatment of diarrhea is estimated to decrease diarrhea mortality by $23 \%$ [5]. Therefore, to reach all children with diarrhea, zinc treatment will need to be introduced and sustained within the public, private and nongovernmental organization (NGO) service-delivery systems [3].

Despite the evidence of benefit, there has been little progress on widespread utilization of zinc for diarrhea treatment and very few children are currently being appropriately treated [6]. Even though, in Somali region zinc is available at public and private health service, and zinc was recommended with ORS, utilization of ORS is higher than Zinc at the national level and in the study area. Therefore; this study is designed to study magnitude of zinc utilization and associated factors among children's having acute diarrhea. Besides, it is great interest to fill the evidence gap of in the eastern Ethiopia.

\section{Method}

\subsection{StudyArea and Study Period}

Kebri-dehar town is one of zonal administrative centre, found in Somali regional state, eastern Ethiopia. There was ten kebeles with total population of 58623 (28,725 males and 29,898 females) and 3,936 households. Among these, from the total population,7042 were under five years old children according to Kebri-dehar town administration report. The study was conducted from February12/2017-March-12/2017.

\subsection{Study Design}

Community based cross sectional study design method was conducted.

\subsection{Study Population}

All mothers with under-five age children with acute diarrhea who live in Kebri-Dhar town were the source population, whereas, selected mothers with under-five age children who have been acute diarrhea living in 10 kebeles were the study population.

\subsection{Sample Size Determination}

By using single population proportion formula, assuming a 95\% confidence interval, $5 \%$ margin of error and $\mathrm{P}=33.4 \%$ Proportion of zinc utilization in Ethiopian was considered [7]. By adding 10\% non-response rate, 376 total sample size were used.

\subsection{Sampling Procedure}

A total 3936 households were found in Kebri-Dhar town, before the actual data collection preliminary survey was done before 14days (because zinc is recommended for 14 day) of the data collection for identifying households with child having acute diarrhea within the last two months from December $12 / 2016$-February $12 / 2017$. From the total number of 7042 children found in Kebri-Dhar town, during preliminary survey 1094 were identified children with acute diarrhea. Proportion allocation formula were used to select children's household with acute diarrhea from each ten kebeles. Study participants were selected using simple random sampling.

\subsection{Data Collection Procedure}

Data were collected using structured interview administered questionnaire adapted from United States agency for international development to the context of the study area recall method [8]. The preliminary survey before the actual data collection was done by twenty nurse. Later ten nurses were collected the data in two weeks while by supervised by two nurses. The questionnaire was first developed in English and then translated into local language "Somali" and back to English to check its consistency. The overall data collection activity was coordinated by the principal investigator.

\subsection{Operational Definitions}

Acute diarrhea: - loose or watery stool for three or more times over 24 hours, lasting less than 14 days [9].

Zinc tablet Utilization: under five age children who had acute diarrhea gets (prescribed) and used zinc tablet.

Appropriate zinc Utilization: Mothers who provides zinc to their children from $10-14$ days without interruption [1].

\subsection{Data Quality Management}

To ensure data quality a pre-tested structured questionnaire was used. On spot checking of the data collection procedure was made. Training was given for the data collectors and supervisors. The completeness of the questionnaire was checked every day and incomplete questionnaires were filed in the following day.

\subsection{Data Processing and Analysis}

The data were first coded, entered using Epi-Data statistical software version 3.1 and then exported into SPSS statistical software version 20 for analysis. A HsomerLemshow and Omnibus test were done to test for model fitting. Bivariate analysis was used to see the association between each independent variable and the outcome variable by using binary logistic regression. All variables with $p$-value $\leq 0.3$ in the Bivariate was taken into the multivariable model to control confounders, and variables was selected by enter 
technique. The odds ratio was used as the primary measure of strength and direction of the relationship between the independent variables. Odds ratio along with 95\% CI was estimated to identify factors associated with zinc utilization The Level of statistical significance was declared at $\mathrm{p}<0.05$ value.

\subsection{Ethical Considerations}

Before starting of the data collection and the preliminary survey, ethical clearance was secured by Haramaya University Institutional Health Research Ethics Review Committee (IHRERC). An Official letter was written from Haramaya University to Kebri-dehar town Municipality and to Kebri-Dhar town Health Office. verbal consent was obtained from each participant for the data collection. Confidentiality of the study participants' information was also ensured by not including their names and personal identification.

\section{Results}

\subsection{Socio-demographic Characteristics of the Study Participant}

A total of 376 mothers with children aged less than five years were included in the study, with a response rate of $99.5 \%$. The mean age of the mothers was $33(\mathrm{SD} \pm 8.3)$ years. About 344 (92\%) of them were married, and 148 (39.6\%) of them attended formal education. About 291 (77.2\%) mothers were housewives. Out of 374 mothers, 178 (47.6\%) of their husbands had formal education. Out of 374 children included in the study, $192(51.3 \%)$ female and $264(70.6 \%)$ of them were not currently on breast feeding. The mean age of these children was 24 ( $\mathrm{SD} \pm 11.8$ ) months. Regarding the feeding habits during acute diarrhea, out of those who reported acute diarrhea, 293 (78.3\%) did not restrict fluid and food during acute diarrhea. The mean duration of acute diarrhea was 5 ( $\mathrm{SD} \pm 2.6)$ days (Table 1).

Table 1. Socio-demographic characteristics of mothers with children less than five years age in Kebri-Dhar town Somali Region, Ethiopia, March2017, $(N=374)$

\begin{tabular}{llll}
\hline Variable & & Frequency & $\begin{array}{l}\text { Percent } \\
(\mathbf{1 0 0 \%})\end{array}$ \\
\hline & $15-19$ & 21 & 5.6 \\
& $20-24$ & 77 & 20.6 \\
Age of mothers & $25-29$ & 18 & 4.8 \\
(n=374) & $30-34$ & 139 & 37.2 \\
& $35-39$ & 19 & 5.1 \\
& $40-44$ & 76 & 20.3 \\
Martial states & $45-49$ & 24 & 6.4 \\
(n=374) & Married & 344 & 92.0 \\
Husband & Divorced & 30 & 8.0 \\
education & Non formal & 196 & 52.4 \\
(n=374) & Primary & 110 & 29.4 \\
mothers & Secondary and above & 68 & 18.2 \\
education & No formal & 226 & 60.4 \\
(n=374) & Primary & 122 & 32.6 \\
Mother & Secondary and above & 26 & 7.0 \\
\hline
\end{tabular}

\begin{tabular}{llll}
\hline Variable & & Frequency & $\begin{array}{l}\text { Percent } \\
(\mathbf{1 0 0 \% )}\end{array}$ \\
\hline occupation & Merchant & 63 & 16.7 \\
& Government employ & 22 & 5.9 \\
Child sex & Male & 182 & 48.7 \\
$(\mathrm{n}=374)$ & Female & 192 & 51.3 \\
Breast feed & Yes & 110 & 29.4 \\
(n=374) & No & 264 & 70.6 \\
Withhold & Yes & 81 & 21.7 \\
(restrict) $(\mathrm{n}=374)$ & No & 293 & 78.3 \\
& Less than 11 month & 49 & 13.1 \\
Child age & 12-23 month & 118 & 31.6 \\
(n=374) & 24-35 month & 135 & 36.1 \\
& 36-47 month & 53 & 14.2 \\
& 48-59 month & 19 & 5.1 \\
Duration & 1-2day & 38 & 10.2 \\
diarrhea (n=374) & 3-4day & 102 & 27.3 \\
& 5-6day & 110 & 29.4 \\
\hline
\end{tabular}

Other*=Amhara, Oromo, Tigray, SNNP.

\subsection{Zinc Tablet Utilization of Study Participant}

Out of the total respondents, the proportion of children who utilized zinc tablet was found to be 109 (29.1\%) (95\% CI, 24.49\%-33.71\%). About 156 (41.7\%) was having information about zinc tablet. During acute diarrhea 78 $(20.9 \%)$ and $28(7.5 \%)$ were utilized zinc tablet until diarrhea stop and for seven days respectively. About $3(0.8 \%)$ of the study participant were appropriately utilized zinc tablet (Table 2).

Table 2. Knowledge attitudes and practice about Utilization of zinc tablet in Kebri-Dhar town, Somali Region, Ethiopia-2017, $(N=374)$.

\begin{tabular}{|c|c|c|c|}
\hline Variable & & Frequency & Percent \\
\hline \multirow{3}{*}{$\begin{array}{l}\text { Information about } \\
\text { zinc }(n=374)\end{array}$} & Yes & 156 & 41.7 \\
\hline & No & 218 & 58.3 \\
\hline & Total & 374 & 100.0 \\
\hline \multirow{3}{*}{$\begin{array}{l}\text { Where do you heard } \\
(n=161)\end{array}$} & Health profession & 90 & 23.4 \\
\hline & Family member & 42 & 11.2 \\
\hline & Mass media & 24 & 6.4 \\
\hline \multirow{7}{*}{$\begin{array}{l}\text { Do you give Zinc } \\
\text { tablet }(n=374) \\
\text { How do you mix } \\
\text { zinc }(n=109) \\
\text { How many days do } \\
\text { you give zinc tablet } \\
(n=109)\end{array}$} & No & 265 & 70.9 \\
\hline & Yes & 109 & 29.1 \\
\hline & Dilute with water & 46 & 12.3 \\
\hline & Dilute with ORS & 63 & 16.8 \\
\hline & Until diarrhea stops & 78 & 20.9 \\
\hline & For 7day & 28 & 7.5 \\
\hline & 10-14day & 3 & .8 \\
\hline \multirow{4}{*}{$\begin{array}{l}\text { When diarrhea Stop } \\
\text { after giving zinc } \\
\text { tablet }\end{array}$} & 1day & 3 & .8 \\
\hline & 2day & 60 & 16.0 \\
\hline & 3 day & 30 & 8.0 \\
\hline & 4day & 16 & 4.3 \\
\hline \multirow{3}{*}{$\begin{array}{l}\text { Why don't give Zinc } \\
\text { tablet }(n=265)\end{array}$} & $\begin{array}{l}\text { Did not know where to } \\
\text { obtain zinc }\end{array}$ & 161 & 43.3 \\
\hline & $\begin{array}{l}\text { Where not prescribed } \\
\text { zinc from clinic }\end{array}$ & 94 & 25.1 \\
\hline & $\begin{array}{l}\text { Unsure about how to } \\
\text { administer zinc }\end{array}$ & 10 & 2.7 \\
\hline
\end{tabular}

\subsection{Results of Multivariable Logistic Regression Analysis}

In the bivariate analysis, father with no-formal and primary education, pastoralist occupation, no-mother formal education and mothers who were withholding food and fluid 
during acute diarrhea were found to be significantly associated with zinc utilization at $95 \%$ confidence level and $P$ value $<0.05$.

In the multivariate analysis, mother with no formal education was $81.9 \%$ less likely $[(\mathrm{AOR}=0.181,95 \% \mathrm{CI}$ : $(0.056,0.591)]$ to give zinc tablet than those mothers with secondary and above level of education. Children whose father had no-formal education and primary level were $95 \%$ and $86.2 \%$ less likely [(AOR $=0.050,95 \% \mathrm{CI}:(0.020,0.128)]$ and $[(\mathrm{AOR}=, 0.138,95 \% \mathrm{CI}:(0.059,0.320)]$ to give zinc tablet than those children whose fathers had secondary and above education respectively. Children whose age was 6-11 months old were found to be $87 \%$ less likely [ $\mathrm{AOR}=0.130$, 95\% CI: $(0.025,0.683)]$ to be given zinc tablet than those children aged 48-59 months. Mothers who were withholding food, and fluid during acute diarrhea were $81 \%$ less likely $[(\mathrm{AOR}=0.185,95 \%:(0.068,0.502)]$ to receive zinc tablet than those who were not withholding (Table 3).

Table 3. Factors associated with zinc tablet utilization in under-five children having acute diarrhea in Kebri-dehar town, Somali Region, Ethiopia in- 2017 $(N=374)$.

\begin{tabular}{|c|c|c|c|c|c|}
\hline \multirow{2}{*}{ Variables } & & \multicolumn{2}{|c|}{ Zinc utilized } & \multirow{2}{*}{ COR 95\% CI } & \multirow{2}{*}{ AOR 95\% CI } \\
\hline & & Yes & No & & \\
\hline \multirow{5}{*}{ Child age } & $6-11$ & 8 & 41 & $0.423(.124,1.444)$ & $0.130(.025, .683)^{*}$ \\
\hline & $12-23$ & 27 & 91 & $0.643(.223,1.853)$ & $0.288(.066,1.264)$ \\
\hline & $24-35$ & 46 & 89 & $1.120(.40,3,139)$ & $0.402(.096,1.713)$ \\
\hline & $36-47$ & 22 & 31 & $1.538(.506,4.67)$ & $0.750(.159,3.3 .533)$ \\
\hline & $48-59$ & 6 & 13 & 1.00 & 1.00 \\
\hline \multirow{3}{*}{ Husband education } & No formal & 18 & 178 & $0.024(.011, .052)$ & $0.050(.020, .128)^{* *}$ \\
\hline & Primary & 36 & 74 & $0.115(.056, .237)$ & $0.138(.059, .320)^{* *}$ \\
\hline & $\begin{array}{l}\text { Secondary and above } \\
\text { education }\end{array}$ & 55 & 13 & 1.00 & 1.00 \\
\hline \multirow{3}{*}{ Mothers education } & No formal & 27 & 199 & $0.050(.019, .130)$ & $0.181(.056, .591)^{*}$ \\
\hline & Primary & 63 & 59 & $0.393(.154,1.004)$ & $0.873(.272,2.794)$ \\
\hline & Secondary and above & 19 & 7 & 1.00 & 1.00 \\
\hline \multirow{2}{*}{$\begin{array}{l}\text { Withhold (restrict) food or } \\
\text { fluid }\end{array}$} & Yes & 6 & 75 & $0.148(.062, .351)$ & $0.185(.068, .502)^{*}$ \\
\hline & No & 103 & 190 & 1.00 & 1.00 \\
\hline \multirow{6}{*}{ Husband occupation } & Pastoralist & 5 & 60 & $0.179(.050, .642)$ & $0.419(.090,1.947)$ \\
\hline & Merchant & 22 & 83 & $0.568(.206,1.564)$ & $0.704(.196,2.528)$ \\
\hline & Government employ & 49 & 53 & $1.981(.745,5.266)$ & $0.849(236 ., 3.060)$ \\
\hline & Non-government employ & 15 & 11 & $2.922(.891,9.581)$ & $1.858(.3948 .761)$ \\
\hline & Daily labor & 11 & 43 & $0.548(.180,1.672)$ & $0.581(.142,2.384)$ \\
\hline & Private & 7 & 15 & 1.00 & 1.00 \\
\hline
\end{tabular}

$*=$ p-value $<0.05, * *=$ p-value $<0.001, \mathrm{CI}=$ Confidence Interval, $\mathrm{COR}=$ Crude Odds Ratio, $\mathrm{AOR}=$ Adjusted Odds Ratio.

\section{Discussion}

The magnitude of zinc utilization was found to be $29.1 \%(95 \%$ CI, $24.49 \%-33.71 \%$ ). This is higher than the studies done in sub-Saharan Africa like Niger (8\%) and Tanzania (3\%) [10], Nigeria (4\%), Bangladesh (25\%) [11], India (18.2\%) [12]. However, it was consistence with the study done in Ghana (29.2\%) [13]. At the sometime, it is lower in magnitude than the study done in Ethiopia at the national level (33\%) and regional level (Somali region) (33.4\%) [7], Addis Ababa (67.1\%) [14], Bangladesh (46\%) [15], and Kenya (82\%) [16]. This difference might be due to socioeconomic and there could be due to the ongoing rollout of policy on zinc utilization and information access difference.

The study showed that age of the children had a significant association with zinc tablet utilization. Children whose age was $6-11$ months old were $86.2 \%$ less likely to utilize zinc tablet than children aged 48-49 months. This was similar with the finding from Kenya Demographic and Health Survey (DHS) [17]. This could be due to caregiver's fear of side effect for the small aged children. The study showed that mothers' educational status had a significant association with zinc tablet utilization for their children who have been acute diarrhea. Mothers who had no formal education were $81.9 \%$ less likely to utilize zinc tablet than those who learnt up to secondary level and above education. This finding was similar with a study done in Ethiopia [7], Kenya [18], Nigeria [19], India [20]. This might due to educated mothers have awareness towards the management of acute diarrhea and can better search means towards the treatment because of access to information they have.

The study revealed that mothers who have been withholding food and fluids during acute diarrhea of the children's had significant association with the utilization of zinc tablet. Mothers who were withholding food and fluids while their child had acute diarrhea were $81 \%$ less likely to utilize zinc tablet for their children than those who are not withholding fluid and food during diarrhea. This finding is supported by a systemic review done in low and middle income countries [21], in Indian villages [22], and India [20]. This could be because of mothers' decision nothing to give due to fear for aggravating acute diarrhea. However, the study was inconsistent with the study done in Kenya in 2013 [16]. This could be due to socio cultural and geographical difference.

The study showed that father education had a significantly association with zinc tablet utilization. Children whose fathers had no formal education were $95 \%$ less likely to 
utilize zinc tablet than those fathers learn up to secondary and above education. This was similar with study done in Bangladesh in [15]. This could be due to educated husbands have access to information from different sources towards the means for the management of the child with the acute diarrhea.

\section{Conclusion and Recommendation}

Zinc tablet where utilized, less than the magnitude of national utilization for children who have been acute diarrhea in the study area. No formal and primary educational of the mothers, age group 6-11 month children, mothers who withholding food and fluid during acute diarrhea and children whose father had No formal and primary educational were significantly associated with zinc utilization. Therefore, improving educational status for both mothers and husbands and providing health education for mothers regarding to the management of diarrhea is an important intervention to boost zinc utilization.

\section{References}

[1] UNICEF, Diarrhoea W. Why children are still dying and what can be done. New York: UNICEF. 2009.

[2] Ambler G, Berry J, Co-founder C, Berry S, Castle B, Clarence $\mathrm{C}$, et al. Proposal to include an additional listing of copackaged ORS and zinc for management of diarrhea in children on the WHO Model List of Essential Medicines for Children. November 12, 2018.

[3] Larson CP, Roy S, Khan AI, Rahman AS, Qadri F. Zinc treatment to under-five children: applications to improve child survival and reduce burden of disease. Journal of health, population, and nutrition. 2008; 26 (3): 356.

[4] DKT/E. DKT/E and micronutrient initiative team up to provide ors - zinc combo product. available at https://www.dktethiopia.org/news/dkte-and-micronutrientinitiative-team-provide-ors-zinc-combo-product. 2013.

[5] CL W, RE B. Zinc for the treatment of diarrhoea: effect on diarrhoea morbidity, mortality and incidence of future episodes. International Journal of Epidemiology. 2010; 39: i63-i9.

[6] Walker CL, Fontaine O, Young MW, Roble. Zinc and low osmolarity oral rehydration salts for diarrhoea: a renewed call to action $2009 ; 780-78(87)$.

[7] CSA., ICF. Ethiopia Demographic and Health Survey Addis Ababa, Ethiopia, and Rockville, Maryland, USA. CSA and ICF. Indicators Report. 2016.

[8] MacDonald., Vicki., Banke K. Toolkit for the Collection of Survey Data on the Correct Use of Pediatric Zinc as a Treatment for Diarrhea. Bethesda, MD: Strengthening Health Outcomes through the Private Sector (SHOPS) Project, Abt Associates Inc.. January 2011..
[9] Organization WH. Diarrhoeal disease Fact sheet. WHO library. 2017.

[10] Carvajal-Vélez L, Amouzou A, Perin J, Maïga A, Tarekegn H, Akinyemi A, et al. Diarrhea management in children under five in sub-Saharan Africa: does the source of care matter? A Countdown analysis. BMC Public Health. 2016; 16 (1): 830.

[11] Larson CP, Saha UR, Nazrul H. Impact monitoring of the national scale up of zinc treatment for childhood diarrhea in Bangladesh: repeat ecologic surveys. PLoS medicine. 2009; 6 (11): e1000175.

[12] Lamberti LM, Walker CLF, Taneja S, Mazumder S, Black RE. Adherence to zinc supplementation guidelines for the treatment of diarrhea among children under-five in Uttar Pradesh, India. Journal of global health. 2015; 5 (2).

[13] El-Khoury M, Banke K, Sloane P. Improved Childhood Diarrhea Treatment Practices in Ghana: A Pre-Post Evaluation of a Comprehensive Private-Sector Program. Global Health: Science and Practice. 2016; 4 (2): 264-75.

[14] Hassen S. Assessment of Utilization of Zinc Tablet and ORS among Under 5 Children with Acute Diarrhea in Akaki Kality Sub-City, Addis Ababa, Ethiopia,; 2016. avilable at http://etd.aau.edu.et/handle/123456789/12397?show=full: Addis Ababa University; 2016.

[15] Akhter S, Larson CP. Willingness to pay for zinc treatment of childhood diarrhoea in a rural population of Bangladesh. Health policy and planning. 2009; 25 (3): 230-6.

[16] Simpson E, Zwisler G, Moodley M. Survey of caregivers in Kenya to assess perceptions of zinc as a treatment for diarrhea in young children and adherence to recommended treatment behaviors. Journal of global health. 2013; 3 (1).

[17] Mukiira CK, Ibisomi L. Healthcare-seeking practices of caregivers of under-five children with diarrheal diseases in two informal settlements in Nairobi, Kenya: University of the Witwatersrand, Faculty of Humanities (Demography and ...; 2012.

[18] Njeri G, Muriithi M. Household Choice of Diarrhea Treatments for Children Under The Age of Five In Kenya: Evidence From The Kenya Demographic And Health Survey 2008-09. European Scientific Journal, ESJ. 2013; 9 (6).

[19] Okoh BA, Alex-Hart BA. Home management of diarrhoea by caregivers presenting at the diarrhoea training unit of a tertiary hospital in southern Nigeria. British Journal of Medicine and Medical Research. 2014; 4 (35): 5524-40.

[20] Choube A, Bahal SP, Srivastava A, Sharma M. Knowledge and child care practices regarding childhood diarrhoea-A cross sectional study. Indian Journal of Community Health. 2014; 26 (3): 285-91.

[21] Carter E, Bryce J, Perin J, Newby H. Harmful practices in the management of childhood diarrhea in low-and middle-income countries: a systematic review. BMC Public Health. 2015; 15 (1): 788 .

[22] Ahmed F, Farheen A, Ali I, Thakur M, Muzaffar A, Samina $M$. Management of diarrhea in under-fives at home and health facilities in Kashmir. International journal of health sciences. 2009; 3 (2): 171. 